\title{
A leitura nas organizações não governamentais e inter-relações com a escola pública
}

Ana Shitara Inglesi

Idméa Semeghini-Siqueira

Universidade de São Paulo

\section{Resumo}

Considerando o baixo grau de letramento dos alunos do ensino fundamental e médio no Brasil e, concomitantemente, o crescimento espantoso do número de organizações não governamentais (ONGs) trabalhando no campo da educação nas últimas décadas, o presente trabalho procura estabelecer uma ponte entre essas duas faces da educação no Brasil. Nesta investigação, pretendeu-se compreender a dinâmica e a influência das ONGs brasileiras, mais especificamente no campo da leitura, tendo em vista o desenvolvimento do letramento. Para tanto, foi realizado um estudo qualitativo, com características etnográficas, baseado, sobretudo, em observações feitas em campo das atividades de uma organização, as quais foram analisadas a partir das concepções de leitura propostas pelos teóricos da psicolinguística (SMITH, 1999, 2003) e da estética da recepção (JAUSS, 1994,2002). Com isso, procurou-se contribuir com os estudos sobre leitura e, principalmente, avançar nessas novas possibilidades educativas que hoje nos são apresentadas pela sociedade civil e que impulsionaram a busca por soluções alternativas para um problema que vem afligindo os educadores há décadas no Brasil. Assim, considera-se que, por meio da troca de ideias e experiências e da implementação de projetos envolvendo leitura, as instituições educacionais não governamentais podem contribuir para o desenvolvimento de uma escola pública de qualidade, sem, no entanto, substituí-la, deixando para o governo a responsabilidade que lhe cabe.

\section{Palavras-chave}

Leitura - ONG - Letramento - Escola pública.

\footnotetext{
Correspondência:
} 


\title{
Reading in non-governmental organizations and interrelations with the public school
}

\author{
Ana Shitara Inglesi \\ Idméa Semeghini-Siqueira \\ University of São Paulo
}

\begin{abstract}
Considering the low level of literacy of pupils in fundamental and secondary education in Brazil and, at the same time, the astounding growth in the number of non-governmental organizations (NGOs) working in the field of education during the last decades, the present work attempts to throw a bridge across those two sides of Brazilian education. The investigation has tried to understand the dynamics and influence of Brazilian NGOs, more specifically in the area of reading, having in mind the development of literacy. To such end, a qualitative study of ethnographic features was conducted based mainly on field observations of the activities of an organization, which were analyzed from the perspectives of reading proposed by the theoreticians of psycholinguistics (SMITH, 1999, 2003) and of the aesthetics of reception (JAUSS, 1994, 2002). The aim was one of contributing to the studies about reading and, in particular, of advancing in the new possibilities of education given to us today by the civil society, which have encouraged the search for alternative solutions to a problem that has plagued Brazilian educators for decades. It is considered that through the exchange of ideas and experiences, and through the implementation of projects involving reading, the educational NGOs can contribute to develop a good quality public school without, however, replacing it, leaving to the state its due responsibility.
\end{abstract}

\section{Keywords}

Reading - NGO - Literacy - Public school.

Contact:

Idméa Semeghini-Siqueira

Alameda Itu, 1043, apto. 62

01421-001 - São Paulo/SP

E-mail: isemeghi@usp.br 
No Brasil, os problemas concernentes à prática da leitura sempre foram fatores de preocupação, sobretudo quando consideramos que ainda são poucos os brasileiros inseridos no universo da língua escrita e que o domínio dessa ferramenta é elemento fundamental para que o homem exerça sua cidadania e possa usufruir de bens culturais produzidos pela sociedade, vivenciando práticas sociais significativas possibilitadas a partir da leitura e da escrita (TEZZARI, 2005).

Quando estudamos os problemas relacionados à leitura, encontramos diversos trabalhos que discutem os entraves que cercam essa questão. No entanto, são poucos os estudos que tratam das organizações não governamentais (ONGs) e dos movimentos sociais ligados à educação, sobretudo por se tratar de um assunto relativamente recente que vem se desenvolvendo no Brasil principalmente a partir da década de 1990.

0 presente artigo pretende começar a suprir essa lacuna e a responder à demanda de estudos que buscam compreender a dinâmica e a influência das ONGs no campo da educação no Brasil. Para isso, partimos da análise das atividades de um grupo de alunos, participantes de uma ONG, no tocante à constituição de leitores e à melhoria do grau de letramento. Assim, por meio de um estudo de caso, analisamos a influência dessa organização no currículo escolar e na metodologia de ensino de literatura nas escolas públicas em que estava presente.

É importante notar como a sociedade civil passou a buscar, nestes últimos anos, soluções para problemas educacionais que, infelizmente, a escola pública não tem conseguido resolver sozinha.

Partindo do pressuposto de que a leitura mobiliza todo o repertório daquele que lê, suas crenças e valores, sua relação com o mundo e com as pessoas que o circundam, de acordo com Carmen Lúcia Eiterer (2001), podemos pensar na leitura como, ao mesmo tempo, socializada e socializadora - o modo como interpretamos o mundo, os estímulos que dele recebemos (sejam imediatos ou mediados por textos) e a leitura que dele executamos são socialmente determinados e mudam ao longo da história.

Tendo esse caráter notadamente social e sendo, concomitantemente, uma atividade cultural, conclui-se que a formação de leitores deve ser uma preocupação para a sociedade como um todo. Assim, a leitura, tanto quanto a literatura, faz parte do mundo escolar, mas não deve, de maneira nenhuma, a ele restringir-se. É importante que a leitura faça parte do cotidiano, da vida fora dos bancos escolares, e esteja presente, repleta de significação, em todos os momentos nas interações do sujeito com o mundo, ou seja, em sua experiência social.

Há fortes evidências de que o desempenho dos alunos está diretamente relacionado aos investimentos feitos nessa área. Foi na busca pela melhoria do nível de letramento que a sociedade civil começou a investir na educação e no estímulo ao prazer da leitura.

Por ser um assunto contemporâneo e cada vez mais presente em nosso dia a dia, o estudo das práticas de leitura nesses novos espaços educativos merece ser aprofundado. Sobretudo, quando podemos neles encontrar uma valiosa ajuda na busca por soluções para problemas antigos e exaustivamente discutidos.

Neste texto, discutiremos a metodologia usada na pesquisa e o aporte das ONGs na transformação da sociedade, bem como sua relação com a leitura no Brasil, a importância social da literatura, os processos envolvidos no ato de ler - contribuições da psicolinguística e da estética da recepção - e o papel do afeto (prazer emocional) e do prazer estético na leitura. Por fim, apresentaremos a pesquisa de campo, justificando a escolha pela $0 \mathrm{NG}$ estudada e, finalmente, os resultados e as análises da pesquisa baseados no quadro teórico apresentado, focalizando as reflexões da ONG sobre leitura e as contribuições decorrentes da proposta em questão. 


\section{Metodologia}

Como forma de estudar o assunto em questão, optamos por fazer um trabalho de campo com duração de um ano e meio, empreendido em uma ONG atuante na cidade de São Bernardo do Campo, São Paulo. Assim, realizamos o que se chama de pesquisa qualitativa sobre o projeto "Círculo de leitura", cujo foco é a constituição de leitores.

A pesquisa qualitativa tem o ambiente natural como sua fonte direta de dados, e o pesquisador como seu principal instrumento. Portanto, esse tipo de pesquisa supõe o contato direto e prolongado do pesquisador com a situação que está sendo investigada, via de regra por meio do trabalho intensivo de campo.

Utilizamos técnicas etnográficas (descrição de um sistema de significados culturais de determinado grupo), sendo a observação participante nossa principal fonte de informação. Dessa maneira, os dados coletados foram predominantemente descritivos, buscando, com isso, descobrir o que se passa na prática diária da ONG para favorecer a melhoria do grau de letramento de seus participantes. Privilegiamos a descrição e o processo de desenvolvimento mais do que o resultado final e, assim, descobrimos novos conceitos, novas relações e novas formas de entendimento da realidade, buscando verificar como a leitura se manifesta nas atividades, nos procedimentos e nas interações cotidianas da ONG.

$\mathrm{Na}$ tentativa de capturar a perspectiva dos participantes - pois, segundo Robert Bogdan e Sari Biklen (1982), o significado que as pessoas dão às coisas e à sua vida devem ser um foco de atenção especial para pesquisador -, e tentando perceber como os participantes do projeto viam as questões relativas à prática da leitura, utilizamos também a entrevista como instrumento de coleta de dados. 0 estudo ainda analisou documentos que nos forneceram um quadro mais vivo e completo da situação.
Os sujeitos da pesquisa foram educandos (alunos do $3^{\circ}$ ano do ensino médio) que participavam do projeto "Círculo de leitura", a professora de português da escola pública em que estudavam e os educadores da ONG, de modo a mapearmos um panorama amplo de suas concepções de linguagem e de leitura.

Usando uma variedade de dados e fontes de informação, esse método de pesquisa possibilitou-nos retratar a realidade de forma mais completa e profunda, revelando a multiplicidade de dimensões presentes numa determinada situação, focalizando-a como um todo e evidenciando a inter-relação entre seus componentes.

\section{- aporte das ONGs na transfor- mação da sociedade e sua rela- ção com a leitura no Brasil}

Ao falarmos das ONGs, é fundamental que possamos discutir seu papel na transformação da sociedade. Elas representam uma das diversas possibilidades que existem atualmente para buscarmos avanços em diferentes setores, tendo sido mais evidentes suas intervenções no campo ambiental e educacional.

Nos últimos anos, a crise do marxismo desfocou as lutas sociais da classe trabalhadora industrial. A ênfase recai hoje na análise da pluralidade dos conflitos sociais e nas novas formas de dominação, enfatizando o poder da produção cultural (TOURAINE, 1989) e das formas de violência/opressão simbólicas (BOURDIEU, 1989).

Nessa nova sociedade, as ONGs possuem um papel importante como geradoras de transformações. Ao intervir diretamente na conjuntura, buscam a ampliação de direitos e a conquista de benefícios sociais, culturais e materiais. Entretanto, analisá-las requer a cautela de verificar suas contradições e heterogenidade. Dentro do vasto campo composto por essas organizações, há aquelas que se institucionalizam em moldes empresariais, reproduzindo 
socialmente a ética capitalista e transformando-se, assim, em um empreendimento lucrativo no qual a questão social é secundária, ou apenas uma justificativa para suas existências.

Por outro lado, felizmente, existem as ONGs voltadas para o atendimento das necessidades sociais. Em geral, estas se originaram de uma tendência à institucionalização dos movimentos sociais. Assim, no sentido de uma maior profissionalização, eficácia nos resultados, captação e otimização de recursos materiais e humanos, as organizações não governamentais se constituiriam como uma forma de apoio e assessoria aos movimentos sociais. Para Ilse Scherer-Warren (1995), elas são grupos com "alguma organização formal que atuam tendo em vista a transformação de aspectos da realidade social considerados como negativos" (p. 162).

Um dos temas mais caros aos movimentos sociais tem sido, por muito tempo, o direito à educação. No Brasil, com as Comunidades Eclesiais de Base (CEBs) e outros órgãos da igreja, a educação foi, desde o princípio, compreendida como um dever também da sociedade civil.

A importância da educação na construção de uma sociedade democrática e na melhoria da qualidade de vida justifica-se não porque a educação em si eleva a renda (apesar de este ser um índice real), mas porque ela fornece alternativas e ferramentas que possibilitam a formação de um ser político (entendido como aquele que reflete, critica e busca soluções) e propicia o fortalecimento democrático ao permitir que os homens tracem seus próprios destinos e o destino de sua sociedade. A educação, portanto, amplia a conscientização e a participação democrática do povo, sendo, assim, libertária e um direito social inalienável.

A constante crise pela qual a educação vem passando no Brasil e o descaso do poder público criaram condições para a proliferação das ações de organizações não governamentais.
Segundo Salete Camba (2004), uma das lutas que se travam agora, no campo educacional, pelos movimentos sociais, é a busca pelo fim do assistencialismo e a luta para influenciar mudanças efetivas nas práticas escolares a fim de uma melhoria na qualidade de ensino das escolas públicas nacionais, o que requer uma transformação profunda na forma como a escola pensa estar ensinando. A relação entre a sociedade civil e a educação baseia-se, então, na busca de novas políticas públicas efetivas para a área.

Camba (2004) explicita, além disso, que,

Com o apoio oferecido pelas instituições que fınanciam projetos na área da educação, o governo deixa de ser a única fonte de recursos para desenvolver as atividades das escolas, embora este ainda seja a principal fonte e o responsável por manter o ensino público e gratuito, que é direito de todo cidadão brasileiro. É aí que entra a nova parceria "sociedade civil e escola", por meio da comunidade, e, onde as ONGs passam a ter uma atuação mais próxima e direta com as escolas públicas. (p.38)

\section{A importância social da literatura:} diálogo humanizador

Dentre as inúmeras questões educacionais abordadas pelas ONGs, escolhemos, no presente trabalho, focalizar a questão da leitura literária como instrumento de humanização.

Segundo Antonio Candido (1995), a literatura seria um elemento importante de humanização, uma vez que humanizar é:

um processo que confirma no homem aqueles traços que reputamos essenciais, como o exercício da reflexão, a aquisição do saber, a boa disposição para com o próximo, o afınamento das emoções, a capacidade de penetrar nos problemas da vida, o senso de beleza, a percepção da complexidade do mundo, dos seres, o cultivo do humor. (p. 249) 
Tendo em vista esse caráter humanizador da literatura, percebe-se o alcance do ato de ler tanto para o indivíduo, quanto para a sociedade na qual ele se insere.

Ao ler, o sujeito não só mantém seu “equilíbrio psíquico" (CANDIDO, 1995, p. 243), como mobiliza e armazena uma gama de repertórios que obteve durante sua vida em contato com os outros, ao mesmo tempo em que aumenta suas experiências. Então, a partir de suas leituras, é muito provável que passe a relacionar-se com o mundo e a agir de maneira diferenciada.

Podemos afırmar que a leitura é um diálogo social sem barreiras temporais que se desenvolveria em um diálogo interno reflexivo e levaria ao desenvolvimento intelectual tanto individual como humanitário, na medida em que a sociedade é composta de homens e de suas ideias.

Assim, ao ler, compreender e dialogar com o que lê, o homem torna-se letrado. 0 fenômeno desse letramento não possui apenas uma dimensão pessoal, mas possui também uma importante dimensão na sociedade. Segundo Soares (2003),

Letramento é o que as pessoas fazem com as habilidades de leitura e de escrita, em um contexto específico, e como estas habilidades se relacionam com as necessidades, valores e práticas sociais. Em outras palavras, letramento não é pura e simplesmente um conjunto de habilidades individuais; é o conjunto de práticas sociais ligadas à leitura e à escrita em que os indivíduos se envolvem em seu contexto social. (p. 72)

Neste sentido, para Paulo Freire (2002), ser alfabetizado é tornar-se capaz de usar a leitura e a escrita como um meio de tomar consciência da realidade e transformá-la.

Portanto, a concepção de leitura que propomos aqui é esse importante diálogo, fundamental na humanização do homem e com um forte caráter social, exatamente por se constituir em um diálogo constante com o outro, seja ele o autor, a época retratada, realidades distintas ou não. Trata-se de um diálogo que, segundo Freire (2002), deve predispor-nos a constantes revisões e que é, sobretudo, uma relação horizontal:

[...] só o diálogo comunica. E quando os dois pólos do diálogo se ligam assim com amor, com esperança, com fé um no outro, se fazem críticos na busca de algo. Instala-se, então, uma relação de simpatia entre ambos. Só aí há comunicação. (p. 115)

Após refletirmos sobre a importância do ato de ler e suas consequências tanto individuais como sociais, buscamos discutir a importância das contribuições da psicolinguística voltadas para a leitura, em especial de textos informativos, e da estética da recepção, referente aos textos literários. Isso porque, ao focalizarem o leitor dentro do processo de leitura, proporcionam-nos ferramentas para que possamos auxiliar a constituição de nossos alunos como leitores, partindo fundamentalmente do papel do prazer estético e afetivo nesse processo.

\section{Questões sobre os processos envolvidos no ato de ler: contribui-} ções da psicolinguística

$\mathrm{Na}$ tentativa de buscar respostas para alguns dos questionamentos acerca do processo de constituição de leitores, Frank Smith (1999) passou a estudar o processo de leitura sob um prisma mais amplo, envolvendo diferentes aspectos cognitivos da leitura, tais como: o conhecimento prévio que cada leitor possui (conhecimento adquirido ao longo da vida), os objetivos e expectativas de leitura, as estratégias de processamento do texto e a interação na leitura de textos (intertextualidade). 
Para o ensino e a aprendizagem, a principal contribuição dos estudos da psicolinguística é o fato de focalizarem o processo de leitura principalmente no leitor, elemento da tríade autor-texto-leitor. Ao ser transformado em um leitor competente, o aluno se tornaria apto a tecer relações necessárias para a construção de sentido e a fazer uso eficiente de diferentes estratégias de leitura. 0 papel do professor seria, então, o de criar oportunidades que permitissem o desenvolvimento do processo cognitivo da leitura de seus alunos.

Segundo Smith (2003), a compreensão decorrente de uma leitura depende dos leitores, das perguntas, das expectativas e das especificações que estes impõem ao texto. Assim,

o significado particular da leitura seria a resposta que o leitor obtém para determinada questão. 0 significado, portanto, também depende das questões que são formuladas. (p. 201)

Essa atividade comunicativa e interativa da leitura é a chave para melhor entendermos os processos envolvidos no ato de ler e os aspectos que devem ser trabalhados nos processos de ensino e aprendizagem, especialmente quando sabemos que essa atividade é mediadora da experiência estética (JAUSS, 2002), fundamental para a constituição do leitor, como veremos no próximo tópico.

Portanto, buscar compreender os aspectos cognitivos da leitura e os conceitos que estão subjacentes a essa faculdade, focalizando sempre o leitor, é fundamental para que o professor possa construir uma prática educacional mais consciente e estratégica no processo de constituição de leitores. Há fortes evidências de que um dos grandes problemas na maneira como a leitura se dá em sala de aula é o fato de ela não apresentar, como diz Angela Kleiman (1995), um objetivo, e de aparecer sempre desvinculada da questão do leitor. Pensamos e refletimos muito pouco sobre quem é o leitor que está na escola, quais são seus conhecimentos de mundo, seus conhecimentos prévios e, sobretudo, seus horizontes de expectativas. Assim, sem levar em consideração esses leitores específicos, não será possível criar oportunidades que permitam o desenvolvimento do processo cognitivo que está subjacente à leitura.

\section{Um olhar sobre a leitura do texto literário: contribuições da estética da recepção}

Considerar a literatura como produção-recepção-comunicação significa que cabe ao leitor atribuir sentido ao texto, partindo de perguntas ou hipóteses (horizontes de expectativas) e fazendo uso de diferentes estratégias cognitivas: o conhecimento linguístico e o extralinguístico (valores e conhecimento de mundo) são fundamentais para a construção do sentido.

Pensando, então, em nossos alunos como leitores dos quais depende a construção do sentido de um texto, é fundamental que se leve em consideração que eles querem encontrar na leitura um reflexo de suas angústias e também de seus prazeres; por isso, faz-se necessário ter em mente as características desses alunos no momento da escolha de livros, de indicações de leitura, bem como a maneira pela qual esta será trabalhada. Se não transformarmos a leitura em uma atividade de prazer e de diálogo, dificilmente conseguiremos fazer com que nossos alunos possam futuramente experienciar criticamente o prazer estético de uma obra de arte.

Ressaltamos que, sem um primeiro contato descompromissado, baseado no prazer da identificação, da catarse, não se pode desenvolver a faculdade de ler. Aqui cabe lembrar a afırmação kantiana do prazer desinteressado próprio da arte, trabalhado por Hans Jauss, e que mais tarde transformou-se, na teoria de Gêiser, no "desinteresse interessado" (LIMA, 2002, p. 22). 
Dessa forma, o prazer de significar, de tornar o texto coerente, deve ser o foco inicial de toda atividade de leitura em sala de aula, para que, mais adiante, os alunos possam dar o grande passo em direção à busca do prazer estético que está no destrinchamento estrutural do texto, no entendimento e na valorização da construção de que resulta o texto bem escrito, seja ele de que natureza for. E é essa importância do prazer estético e da doutrina dos afetos que será tratada no próximo segmento deste texto.

\section{O papel do afeto (prazer emocio- nal) e do prazer estético no âmbi- to da estética da recepção}

Dentro do escopo fornecido pela estética da recepção, gostaríamos, neste artigo, de aprofundar um aspecto fundamental que julgamos estar conectado a todos os outros, servindo de ponto de partida para a aproximação do aluno com a leitura: o desenvolvimento do prazer estético e a importância do afeto/prazer emocional na constituição de leitores.

Se considerarmos, a princípio, que a leitura possui três dimensões - afetiva (como nos sentimos em relação ao que estamos lendo e ao próprio ato de ler), cognitiva (saber/conhecimento) e pragmática (estratégias para interagir com o texto) -, pode-se concluir que todas essas dimensões estão envolvidas no que chamamos de prazer estético.

No entanto, para que o leitor consiga atingir o prazer estético e caminhar por essas três dimensões, é preciso que, num primeiro momento, exista uma identificação dele com algum aspecto do texto, o que desencadearia um prazer emocional ligado à dimensão afetiva. Ou seja, é necessário que a leitura propicie um momento de catarse aristotélica, pois, segundo Jauss (1994),

[...] o espectador (no caso leitor) pode ser afetado pelo que se representa, identificar-se com as pessoas em ação, dar assim livre curso às próprias paixões despertadas e sentir-se aliviado por sua descarga prazerosa como se participasse de uma cura (katharsis). (p. 86-87)

Por isso, os contatos iniciais com a leitura, desde o nascimento, nas relações familiares, passando pela educação infantil e os anos iniciais do ensino fundamental, devem priorizar a dimensão afetiva e o pilar da magia/estética para que, então, a criança seja seduzida para o universo da leitura.

Colocar o prazer estético como a orientação fundamentadora da experiência estética corresponde à própria concepção de leitura do presente trabalho, uma vez que acreditamos, como o referido autor, na correspondência entre a experiência estética e as outras áreas de significação da realidade cotidiana, e que um dos valores da arte está nesse entrelaçamento da experiência humana.

Quando se pensa no leitor iniciante e em constituição de leitores, sejam eles crianças, jovens ou adultos, torna-se cada vez mais evidente que a aproximação inicial com a leitura deve fazer-se, primeiramente e sobretudo, por meio do afeto e do prazer primário, oriundo do efeito estético de uma dada obra. A compreensão fruidora é o primeiro passo para seduzir o sujeito para o mundo das letras. Smith (2003) explica-nos que se a criança não consegue extrair sentido daquilo que se espera que ela aprenda, ela sente tédio, e a falta de estímulo, aliada ao medo de cometer erros, torna-a relutante em aprender. Assim, não devemos buscar, logo de início, transformar o prazer da leitura em uma complexa e complicada trama de interpretações, com o risco de criarmos bloqueios que impedirão o desenvolvimento da prática da leitura.

Evidentemente, a reflexão, a busca de interpretação e a reconstrução dos sentidos são essenciais no processo de leitura; porém, não devemos considerar essa postura racional e crítica mais importante do que o prazer 
da experiência humana primeira que ocorre por meio da comunicação, nem devemos esperar tal postura de nós mesmos e dos leitores iniciantes o tempo todo.

Com isso, Jauss (1994) não quis dizer que o prazer estético se limita a esse primeiro contato com a obra de arte. Ele afirmou que tal prazer libera da obrigação prática do trabalho, mas não se opõe ao conhecimento nem à ação.

0 prazer estético exige também um momento crítico que exclui a existência do objeto e transforma-o em objeto estético: assim, o sujeito participa da produção da obra de arte e dela se apropria, de acordo com seu nível de identificação e sua biografia particular.

Essa apropriação e essa coprodução do objeto de arte (atividade reflexiva e crítica) só podem ser desenvolvidas pelo sujeito depois que este teve seus sentimentos evocados, liberando-se da existência cotidiana por meio do prazer. Parece-nos bastante relevante a afırmação de Jauss (1994) de que "a comunicação literária só conserva 0 caráter de uma experiência estética enquanto a atividade da poiesis, da aisthesis ou da katharsis mantiver o caráter de prazer" (p. 96).

Aqui lembramos que a mediação de um adulto (professor) mostra-se fundamental para o aluno aprimorar suas habilidades de leitura e tornar-se um leitor competente, o qual passa da experiência primária para o ato de reflexão, sobretudo quando o professor busca fazer com que o aluno compreenda como a obra se estrutura e quais são os recursos estéticos e linguísticos que causam o prazer. A própria palavra prazer, em alemão, possui o sentido de "participação e apropriação” (JAUSS, 2002, p. 85), lembrando mais uma vez o papel do leitor na construção de seu próprio prazer. 0 ato da reflexão que deve seguir-se ao prazer emocional para constituir-se em um prazer estético é fundamental, uma vez que transforma os textos lidos em espaço de interação, tendo em vista a constituição de leitores críticos, como explica Jauss (2002) em duas passagens:
Enquanto o eu se satisfaz no prazer elementar, e este, enquanto dura, é auto-suficiente e sem relação com a vida restante, o prazer estético exige um momento adicional, ou seja, uma tomada de posição, que exclui a existência do objeto e, deste modo, o converte em objeto estético. (p. 96)

Em face disso, a atitude estética exige que o objeto distanciado não seja contemplado desinteressadamente, mas que seja co-produzido pelo fruidor [...]. (p. 98)

\section{Pesquisa de campo e seleção da ONG}

0 que constatamos na primeira etapa desta pesquisa, ao visitar cinco organizações não governamentais antes de partirmos para o estudo de campo propriamente dito, foi muita boa vontade, mas também muito amadorismo. A partir de entrevistas realizadas com os coordenadores dos projetos, percebemos que todas as organizações procuravam melhorar a qualidade de vida da população atendida por meio do investimento na educação de seus alunos; no entanto, verificamos que faltava muito fundamento teórico.

Em tais espaços, percebemos a ausência de projetos pedagógicos e de sistemas de avaliação. A maior parte parecia permanecer no que chamamos de atuação por intuição, sem reflexão ou direcionamento de suas atividades para o melhor desenvolvimento cognitivo e afetivo/pessoal de seus educandos. Mesmo tendo o cuidado de contratar profissionais da área da educação, suas atividades não eram direcionadas. A preocupação com o projeto pedagógico e o estudo de práticas e de ciências da educação não pareceram ser uma questão central para elas.

0 fato mais alarmante, no entanto, foi a falta de preocupação da maioria das ONGs visitadas em relação à escola pública. A fraca atuação e o fraco relacionamento destas com 
as escolas mostram distanciamento e desinteresse no auxílio e na melhoria do sistema público de ensino, o que não acrescenta muito à sociedade e, principalmente, não a ajuda a transformar-se.

Essas organizações não buscam influenciar as práticas educativas da escola nem sua gestão e, por isso, mantêm-se à margem da comunidade. Não há interação entre escola e ONG, ou, quando há, ela se limita à troca de fichas de alunos, o que não ajuda a estabelecer melhorias. 0 trabalho paralelo das organizações pouco acrescenta para a coletividade, ou talvez acrescente apenas em nível individual, mas isso também não pode ser avaliado, visto que as organizações não possuem um processo avaliativo para comprovar a melhora e/ou o desenvolvimento cognitivo dos indivíduos participantes. Assim, afirmamos que, se as propostas educativas da sociedade civil nunca chegarem à escola e a um número maior de alunos, o trabalho dessas ONGs estará incompleto e a escola pública permanecerá sendo criticada, sem ajuda e sem intervenções positivas.

Partimos dos dados apresentados no quadro 1 para fundamentar nossa escolha da ONG 6 como local para realizarmos nosso estudo de campo, sobretudo por ela possuir um projeto pedagógico (o que nenhuma das ONGs anteriormente estudadas apresentou), um sistema de avaliação, o objetivo de influenciar/ atuar diretamente na escola e, finalmente, um programa direcionado especificamente para a constituição de leitores e para o desenvolvimento do letramento.

\begin{tabular}{|c|c|c|c|c|c|c|c|c|}
\hline & Fundação & Fundador & $\begin{array}{c}\text { Projeto } \\
\text { pedagógico }\end{array}$ & $\begin{array}{l}\text { Sistema } \\
\text { de } \\
\text { avaliação }\end{array}$ & $\begin{array}{l}\text { Profissionais } \\
\text { da área de } \\
\text { educação }\end{array}$ & Biblioteca & $\begin{array}{l}\text { Projeto de } \\
\text { leitura }\end{array}$ & $\begin{array}{l}\text { Relação com } \\
\text { a escola }\end{array}$ \\
\hline $\begin{array}{c}\text { ONG } \\
1\end{array}$ & 1992 & $\begin{array}{l}\text { Terapeutas } \\
\text { florais }\end{array}$ & $\begin{array}{l}\text { Não - em } \\
\text { andamento }\end{array}$ & Não & Sim & $\underset{\text { ruim }}{\operatorname{Sim}-}$ & Não & $\begin{array}{l}\text { Fraca - quase } \\
\text { inexistente }\end{array}$ \\
\hline $\begin{array}{c}\text { ONG } \\
2\end{array}$ & 1998 & Atletas & $\begin{array}{l}\text { Não - em } \\
\text { andamento }\end{array}$ & Não & Sim & Sim - boa & $\mathrm{Sim}$ & $\begin{array}{l}\text { Fraca - quase } \\
\text { inexistente }\end{array}$ \\
\hline $\begin{array}{c}\text { ONG } \\
3\end{array}$ & 1997 & Jornalista & $\begin{array}{l}\text { Não - mas mostrou } \\
\text { embasamento } \\
\text { teórico }\end{array}$ & Não & Sim & Não & Não & $\begin{array}{l}\text { Sim - diálogo } \\
\text { e cursos para } \\
\text { professores }\end{array}$ \\
\hline $\begin{array}{c}\text { ONG } \\
4\end{array}$ & 1991 & Educador & $\begin{array}{l}\text { Não - mas mostrou } \\
\text { embasamento } \\
\text { teórico }\end{array}$ & Não & Sim & $\begin{array}{c}\text { Sim - } \\
\text { ruim, só } \\
\text { consultas } \\
\text { locais }\end{array}$ & Não & $\begin{array}{l}\text { Sim - gestão } \\
\text { escola cidadã }\end{array}$ \\
\hline $\begin{array}{c}\text { ONG } \\
5\end{array}$ & 1975 & Educador & $\begin{array}{l}\text { Não - mas mostrou } \\
\text { embasamento } \\
\text { teórico }\end{array}$ & Não & Sim & $\begin{array}{l}\text { Sim - } \\
\text { regular }\end{array}$ & Não & Não há \\
\hline $\begin{array}{c}\text { ONG } \\
6\end{array}$ & 1987 & $\begin{array}{l}\text { Jornalista e } \\
\text { Analista }\end{array}$ & Sim & Sim & Sim & Não & Sim & $\begin{array}{l}\text { Sim - } \\
\text { intervenção } \\
\text { direta nas } \\
\text { atividades } \\
\text { e na grade } \\
\text { horária. }\end{array}$ \\
\hline
\end{tabular}

Quadro 1 - Quadro comparativo de tópicos analisados nas seis ONGs observadas: dados colhidos por meio de entrevistas e acesso à documentação. 
De modo geral, o projeto "Círculo de Leitura" da ONG 6 tem obtido bons resultados e é visto com bastante credibilidade pelas diretorias das escolas estaduais em que atua. 0 projeto iniciou-se no município de São Bernardo do Campo, atuando em centros de juventude do governo municipal e estadual. Com o passar do tempo, ganhou mais visibilidade e a própria Secretaria da Educação Municipal procurou a ONG para que esta levasse seu projeto às escolas.

Os círculos de leitura são grupos de educandos que se reúnem uma vez por semana com um educador da ONG para realizarem uma sessão de leitura. Sentam-se sempre em círculo e leem em voz alta, interrompendo a leitura para comentarem, perguntarem e dialogarem. Ao final da sessão, escrevem seus pensamentos sobre o que foi lido e discutido. A atividade é sempre coordenada pelo educador, que busca instigar a reflexão e promover a participação dos educandos, dando assim oportunidade e espaço para que estes possam expressar-se.

0 contato com as escolas é feito, primeiramente, com a direção/coordenação, para quem o projeto é apresentado. Se aceito, o projeto é levado para os professores e, durante o HTPC (Horário de Trabalho Pedagógico Coletivo), é promovido um círculo de leitura e oficinas com os próprios professores. Posteriormente, a ONG solicita aos professores que divulguem o projeto junto a seus alunos, bem como que indiquem aqueles alunos cujo interesse julgam promissor. Assim, após as indicações, o projeto começa a ser realizado com os alunos. A indicação dos educandos, feita pelas professoras que participam do projeto, é defendida pelas coordenadoras da ONG, pois estas acreditam que se o grupo não for constituído por educandos interessados, as atividades não serão bem-sucedidas.

A maior parte dos círculos de leitura ainda acontece fora do horário de aula; porém, no ano de 2007, algumas escolas, a pedido da própria direção, requisitaram que as ativida- des da ONG ocorressem durante o período de aula, fazendo parte da grade escolar, o que representou um enorme avanço em termos de influência da sociedade civil nas políticas públicas de educação do município em questão.

Na ONG estudada, há uma clara preocupação em intervir e modificar as práticas de ensino nas escolas públicas, algo que não vimos anteriormente. Essa intervenção é fundamental para que se socializem numa escala bem maior as mudanças e as práticas de ensino trazidas pelas ONGs, o que pode provocar uma verdadeira transformação no ensino. 0 trabalho para incluir as atividades na escola é importante para que esta ganhe autonomia e dê continuidade ao projeto, de modo a suspender uma ação assistencialista e promover uma verdadeira ação em parceria que não cria laços nocivos de dependência.

No presente trabalho, procuramos ressaltar a importância da ação social da ONG 6 para fazer com que a ampliação do grau de letramento por meio da leitura prazerosa seja um instrumento de inserção social e de socialização do conhecimento, o que favorece a formação de verdadeiros atores sociais que não se submetam a mecanismos simbólicos que permitam a perpetuação de desigualdades (MARX, 2002).

\section{Análise da proposta da ONG 6 sobre a leitura}

A análise documental da proposta metodológica do projeto e das observações registradas ao longo da pesquisa de campo indica que a ONG 6 estudada possui uma visão muito clara do que, para ela, representa a leitura e o acesso aos bens culturais. Essa visão está diretamente relacionada à formação acadêmica e profissional da idealizadora do projeto - filósofa e psicanalista - e permeia, frequentemente, também as falas de seus participantes. Segundo o folder produzido pela organização, 
Este método busca desenvolver o gosto e o interesse pela leitura entre crianças e adolescentes de baixa renda em comunidades urbanas de periferia. A leitura tem a função de ampliar o universo cultural-afetivo desses jovens, normalmente bastante restrito. (grifo nosso)

É interessante que a questão afetiva apareça logo nos objetivos do projeto, uma vez que, no âmbito da fundamentação teórica por nós apresentada, o prazer emocional (estética da recepção), ligado à afetividade, deve ser um dos elementos principais na conquista dos jovens leitores, tal como discutido anteriormente. A própria idealizadora do projeto e alguns participantes, no decorrer de nosso convívio, usaram a palavra sedução para justificar o sucesso ou o fracasso do projeto em determinado caso. Assim, para a $0 N G$, é fundamental que haja uma sedução para o universo da leitura, a partir, sobretudo, do afeto e da emoção.

Segundo Jauss (1994), a experiência emocional é essencial para o desencadeamento do processo de leitura:

A experiência estética não se inicia pela compreensão e interpretação do significado de uma obra; menos ainda, pela reconstrução da intenção de seu autor. A experiência primária de uma obra de arte realiza-se na sintonia com (Einstellung auf) seu efeito estético, isto é, na compreensão fruidora e na fruição compreensiva. Uma interpretação que ignorasse esta experiência estética primeira seria própria da presunção do filólogo que cultivasse o engano de supor que o texto fora feito, não para o leitor, mas sim especialmente, para ser interpretado. (p. 69)

Apesar de a ONG defender o trabalho com a leitura a partir do que chamamos de prazer emocional, ao longo da pesquisa, ela demonstrou desprezar o pensamento intelectual e analítico, próprio do prazer estético. A ênfase no sentimento e na parte afetiva, bem como a busca pela catarse aristotélica defendida por Jauss (1994), são elementos que possuem valor fundamental na constituição de leitores; porém, há um equívoco quando se exclui o trabalho intelectual/ racional do ato de ler, como também vimos anteriormente. 0 desenvolvimento do prazer estético não se constituiu como a intenção principal do trabalho da organização em questão, e a ONG parece estagnada nessa etapa da leitura (prazer emocional), não realizando o salto com seus participantes em direção ao prazer estético e reflexivo.

Posteriormente compreendemos que a leitura estava no projeto como pretexto e ponto de partida para a discussão sobre os próprios participantes e outros temas universais a eles pertencentes. Não se trata, portanto, de uma aula de literatura ou de uma discussão literária; não se trata de discutir a forma, os gêneros, seu contexto histórico e seu impacto na sociedade e na cultura. 0 "Círculo de Leitura" focaliza a leitura a partir dos temas e questões levantadas pelos textos. Coube-nos perguntar se o que envolve os educandos é mesmo a leitura literária ou a possibilidade de discutir e estar em grupo, de participar de uma terapia em grupo, e se, efetivamente, um poderia levar ao outro e vice-versa.

A proeminência dos aspectos psicanalíticos acaba, por vezes, reduzindo os aspectos que podem ser levantados na leitura, tornando a proposta do projeto bastante unitária e restrita. Sendo a realidade múltipla e os olhares dirigidos de diversos ângulos, não nos parece interessante evitar outras possibilidades que a leitura nos possa fornecer, outras maneiras de criticar um texto.

Apesar disso, a ONG percebe o valor social e humanizador da leitura como defendido pelo professor Antonio Candido no início deste artigo, e, sobretudo, considera também a leitura como um diálogo social, uma atividade comunicativa e interativa, tal como exposto anteriormente: um diálogo que humaniza e que é nossa herança cultural. De acordo com o folder da ONG, 
De forma geral [no mundo atual] acentua-se a tendência ao individualismo, à supervalorização dos bens materiais, à busca do prazer imediato facilmente descartável e substituível, ao sucesso rápido. Nesse contexto torna-se difícil a formação de uma identidade coerente e segura, que para se consolidar depende de parâmetros firmes. [...] Tais parâmetros nos chegam somente através de uma sabedoria estruturada em séculos e séculos de experiência, de história, de contato com a natureza e com o patrimônio cultural que chegou até nós. A linguagem humana [...] escrita sempre se encarregou de difundir, ampliar, imortalizar para a posteridade uma herança inigualável. E é esta que buscamos transmitir a estes jovens e crianças, com os quais entramos em contato.

É possível que, a partir da leitura dos textos literários e do incremento da autoestima desses educandos, no processo que os faz identificarem-se como leitores (fazendo-os perceber que podem ler qualquer obra, que possuem capacitação para tal e que a leitura leva à reflexão prazerosa), haja mais chances de que eles tornem-se leitores autônomos e críticos.

No entanto, observamos também que a maioria dos educandos não lia por iniciativa própria, no seu tempo livre. Os educandos compareciam aos círculos de leitura, nos quais eles liam, discutiam e apreciavam; todavia, continuavam não lendo fora dos círculos, nem o texto trabalhado em grupo, nem outros textos escolhidos livremente. 0 costume de ler não estava, até o momento, sendo incorporado pela maior parte dos participantes. Esses aspectos, de certa forma, reforçam nossa hipótese de que a convivência e as discussões em grupo teriam mais importância do que a leitura por si mesma para os participantes do projeto:
Tiago: Não, só leio no círculo. [...] Não tô lendo mais não.

Natália: Não, não muito. Antes eu lia mais...Porque agora eu tenho a escola, depois eu tenho o treino, depois eu tenho trabalho, eu não tenho tempo. Aí a noite, eu tomo banho e vou dormir, praticamente. Aí eu não perco meu tempo, o pouco tempo de sono. Eu não tenho tempo. [...] Não. Não leio fora do círculo, só revistas.

Carla: Não, porque é falta de tempo. Chego do curso, jogo as coisas e vou arrumar a casa para a minha mãe...

Acreditamos que o problema enfrentado pelo projeto (a não constituição de leitores) talvez esteja relacionado à sua própria base teórica. A bibliografia do projeto aponta para uma direção psicanalítica, estando bastante carregada de livros de psicanálise e filosofia e com poucas referências a trabalhos de crítica literária e, muito menos, de ciências da educação.

Se a proposta é "desenvolver o gosto e o interesse pela leitura", tal como afirma o folder da ONG, há um descompasso entre esse objetivo e sua base teórica. Há muita psicanálise e pouca teoria sobre leitura e práticas educativas. A ONG 6, como mencionado anteriormente, usa a leitura como meio para ampliar o universo cultural-afetivo dos educandos, buscando, dessa forma, ajudar a construir suas identidades. Ou seja, a leitura para eles é um meio e não um fim, um objetivo a ser atingido (o desfrute do prazer estético), como nos faz crer sua proposta. Se realmente a proposta não for focalizada no trabalho com a leitura, mas na constituição de identidade, ela deve ser alterada.

Partimos ambos (a ONG e nós) da concepção de que leitura é uma recepção não passiva de mensagem que serve para dialogar com o mundo e constituir-se como sujeito histórico e social, e de que essa prática do diálogo mediado pela leitura é uma prática libertadora. 
Entretanto, mesmo essas concepções estando subjacentes aos trabalhos e às intenções da ONG, esta, ao restringir-se ao prazer emocional e não direcionar os educandos também ao prazer estético, limita seu trabalho na medida em que não torna os alunos capazes de discernir entre uma leitura de qualidade artística/estética e um simples produto comercial que não propicia diálogo nem possibilidade de reflexão e, portanto, não colabora com a constituição de um sujeito social.

0 trabalho com a leitura voltado à constituição da identidade pode ser ainda mais problemático, não só por empobrecer a prática da leitura, mas por poder cair facilmente no moralismo, na antiga concepção de literatura infantil segundo a qual a leitura deveria servir somente para o que se chamava "constituição de caráter" (COELHO, 2002).

\section{Análises e resultados}

Constatamos, primeiramente, a preferência da ONG 6 em focalizar os acertos e em optar por escolher os melhores educandos de cada grupo (alunos indicados pelos professores) para estimular e desenvolver suas capacidades. Trata-se de um mecanismo de autossustentação do projeto, na medida em que continuam formando multiplicadores e educadores e, assim, vão expandindo as atividades para outras escolas. No entanto, restou-nos a seguinte questão: e aqueles educandos que nunca tiveram prazer em ler, aqueles já marginalizados pelo sistema escolar que não vão espontaneamente participar dos círculos?

Entre os alunos participantes, tivemos evidências de que muitos melhoraram seu desempenho tanto no que se refere à capacidade de interpretar um texto, decorrente de maior concentração na leitura, quanto à organização de seu pensamento e, algumas vezes, ao desenvolvimento do prazer estético. A maioria afirma ter expandido seu vocabulário e melhorado sua fluência na leitura em voz alta, bem como ter obtido melhoria da expressão oral, da concentração, da reflexão e da compreensão leitora. Todos esses ganhos cognitivos são importantíssimos para esses alunos e certamente melhoraram seu grau de letramento, transformando a mera decodificação de um texto em diálogo e aprendizado. Isso os ajudou a tornarem-se mais críticos, a dialogarem com a sociedade e, portanto, a instaurarem-se como sujeitos:

Laura: Ajudou a desenvolver a minha mente, fiquei, sei lá, com a mente mais aberta, assim, em relação a outras pessoas que eu via lendo, mó espontânea ali, explicando, entendeu? E hoje eu já sei ler uma coisa e explicar para as pessoas... porque nem todos tem a mesma visão.

Taís: Mudou o meu jeito de ver a leitura, a gente aprende a pronunciar as palavras melhor, a conviver em grupo, a entender as ideias das outras pessoas. [...] Depois do círculo de leitura, eu comecei a ver o modo de ler diferente, porque antes era só uma leitura, mais uma estória, e agora, depois do círculo de leitura, eu vejo que não é MAIS só uma estória, é uma estória que quer passar alguma coisa para as pessoas.

Cauê: Então, o que eu falei de interpretação, consegue ficar bem mais fácil, você aprende aqui a interpretar. [...] depois do círculo de leitura, você começa a prestar mais atenção nos mínimos detalhes que nem dava bola; eu presto mais atenção.

Tiago: Eu tô pensando mais. Antes eu lia só por ler, não conseguia absorver o que estava passando. Agora é melhor.

Como nossa intenção neste trabalho era saber se a ONG em questão estava contribuindo para a constituição de leitores e para a melhoria do grau de letramento dos alunos da escola pública, concluímos que, nos limites do observado, o projeto "Círculo de Leitura" da ONG 6 não atingiu o objetivo, por ela declarado, de 
desenvolver o gosto e o interesse pela leitura, uma vez que geralmente trabalha com jovens que já se interessam pela leitura e não precisam desenvolver o gosto, como observamos a partir de entrevistas realizadas:

Laura: Eu não gostava MUUUITO assim, mas gostava, era vergonha mesmo, e eu perdi essa vergonha mesmo de ler, de tudo. Eu gosto de ler desde sempre, porque eu acho mó bonito ver as pessoas, as professoras lendo, assim, eu sempre achei bonito.

Taís: Eu sempre gostei de ler. Eu gosto de tudo o que me interessa, eu nunca tenho assim um objetivo, eu gosto só de drama, ou só de ficção, de tudo um pouco, depende. Não tenho um tipo favorito.

Cauê: Gosto, gosto. Nem sempre eu gostei. Comecei a gostar quando eu li Harry Potter, faz uns 4 anos. Acho que na $6^{\text {a }}$ série...

Penélope: Eu comecei a gostar mais de ler assim, quando eu comecei a ler gibi, né? Aí comecei a ter o hábito e a ler sempre mais... Mas, eu sempre tive o hábito de ler.

Com isso, a ONG afirma que o projeto tem sucesso, ignorando as faltas e os problemas de evasão, e, assim, não busca realizar melhorias, traçando, de certa forma, um panorama enganoso do projeto. Ao negligenciarem o trabalho com jovens que não se interessam pela leitura, ela não colabora com a formação de novos leitores. Portanto, podemos afırmar que a ONG não tem ajudado efetivamente na constituição de leitores, mas tem, por ora, colaborado para aprimorar o nível de letramento dos alunos atendidos. Assim, nossas hipóteses só se confirmaram em parte.

No entanto, foi interessante notar que, ao procurar descobrir se a ONG 6 conseguia de fato despertar o prazer da leitura, outro resultado emergiu. Fomos verificar o estabelecimento de relações entre os jovens e a leitura e encontramos a importância do estabelecimento de relações entre os próprios jovens e o fortalecimento de sua autoestima, tanto consigo mesmos como em relação à leitura.

Os vínculos afetivos e a sociabilidade juvenil têm um papel central no sucesso do projeto entre os seus participantes. A construção da identidade, o estabelecimento de relações interpessoais saudáveis, a liberdade de expressão, o direito à escuta e à consideração foram elementos decisivos para o desenvolvimento do letramento desses jovens e para a melhoria de seu desempenho escolar. 0 trabalho com a autoestima e com a ampliação do universo cultural-afetivo proposto pela organização foi um sucesso. Assim, apesar de não ampliar o gosto e o interesse pela leitura, a ONG 6 conseguiu, no entanto, tornar seus educandos pessoas mais confiantes em si mesmas, que se consideram mais inteligentes depois da participação no projeto e que possuem agora mais recursos e conhecimentos para a vida:

Laura: É... é difícil falar uma coisa só que eu goste no círculo. [...] Sei lá, a gente consegue viajar e é opiniões diferentes, saber respeitar opiniões dos outros, e eles também respeitam a minha opinião, então é uma coisa que, não tem aquela opinião... o professor [educador] Renato, fala uma coisa, a gente dá opinião e talvez não é a mesma dele, mas no círculo ele aceita, sei lá viajando junto com a nossa opinião. [...] $\mathrm{Na}$ aula, tem alguns professores que não aceitam a nossa opinião, quer dizer aceitam, mas não tanto quanto aqui. Aqui a gente desenvolve mais, e vai mais além

Assim, como vimos, o objetivo de desenvolver o gosto e o interesse pela leitura precisaria ser revisto pela organização que, na realidade, foca o trabalho na ampliação do universo cultural-afetivo dos alunos, principalmente ao fortalecer suas autoestimas. A 
sensação de pertencimento e respeito nos círculos de leitura é fundamental para o sucesso do projeto. 0 enfoque no desenvolvimento da identidade deve-se à visão terapêutica da idealizadora da ONG 6, ela mesma psicanalista. Dessa forma, concluímos que a preocupação com a leitura e o desenvolvimento do prazer estético perpassa o projeto, mas não é seu foco principal.

\section{Considerações finais}

0 problema que motivou esta pesquisa originou-se da constatação do baixo grau de letramento da população brasileira, e, portanto, do fracasso do ensino público em constituir leitores. $\mathrm{Na}$ expectativa de encontrar soluções para essa questão, voltamos-nos para a sociedade civil em busca de novas propostas.

A nova mentalidade, a visão de mundo e as práticas metodológicas apresentadas por tais ações sociais são respostas a problemas existentes há muito tempo na sociedade complexa. A ação voluntária da sociedade civil permite autonomia e também possibilita pressionar as autoridades públicas, anunciando mudanças possíveis. São ações como a do "Círculo de leitura” que preparam modelos que serão utilizados por instituições (nesse caso, o sistema público de ensino de São Bernardo do Campo), colaborando para o fortalecimento da democracia e também, como vimos neste estudo, para a melhoria da educação e do estímulo à prática da leitura e do desenvolvimento do letramento.

A ONG 6 e o projeto "Círculo de Leitura" ensinaram-nos a importância do trabalho para fortalecer a autoestima dos alunos do sistema público de ensino. 0 fortalecimento da autoimagem e a sociabilização em um ambiente seguro, em que sua inteligência é valorizada, favorecem a melhoria do letramento e de qualquer atividade cognitiva.

Para que o projeto seja realmente bem sucedido na constituição de novos leitores, consideramos fundamental que a ONG 6 se abra para um diálogo inicial e verdadeiro com os jovens, procurando entendê-los em suas realidades (de leitores moventes) e em suas fontes de interesse (SMITH, 1999). Isso ajudaria a melhorar as escolhas de leituras e a atrair mais alunos. Seria também importante que seus educadores possuíssem uma base mais sólida em questões educacionais e literárias, além de buscarem focalizar um pouco mais a escrita e a reescrita dos textos dos alunos como forma de retomar as leituras e de ajudá-los a aprender como organizar o próprio pensamento por meio da escrita. Quando pertinentes, outras linguagens poderiam ser empregadas, como a música, a pintura ou o cinema, além do incentivo a leituras individuais para estimular preferências e formar leitores autônomos.

0 principal feito da ONG 6 talvez seja que as atividades analisadas, apesar de ainda não estarem atingindo seu objetivo na formação de leitores, estão transformando as práticas de ensino na rede pública, em especial da literatura, pois participam das atividades diárias dos alunos dentro da grade horária, como atividade optativa (aula de língua portuguesa ou "Círculo de Leitura"). A ONG 6 tem-se preocupado em influenciar e intervir na escola pública, buscando com isso auxiliar na melhoria do ensino. É importante, no entanto, que as atividades atinjam todos os alunos e ampliem seu campo de atuação, estendendo os benefícios democraticamente e, assim, realmente influenciando de forma efetiva o sistema da educação pública.

Concluímos que a sociedade, por meio das ONGs, pode ajudar a escola a desenvolver-se de diferentes formas, inclusive tornando-a mais aberta à sociedade. Apesar de algumas inadequações, a ONG 6 colaborou para a melhoria do grau de letramento dos alunos participantes do projeto, mas foi excludente e não ajudou a constituir novos leitores no "Círculo de Leitura". 
Ainda assim, sua colaboração foi efetiva e importante para a escola.

Dessa forma, a colaboração emergente de tais iniciativas, as quais nunca devem ser excludentes, como infelizmente ainda constatamos, pode ter grande valor para a melhoria da escola pública. Dialogando e levando até ela alternativas que possam ser vivenciadas no ambiente escolar, lançando um novo olhar sobre a escola, criando espaços de troca e mobilizando a sociedade, será dado mais um passo na melhoria do ensino como um todo e, quem sabe um dia, também na constituição de novos leitores.

\section{Referências}

BOGDAN, R.; BIKLEN, S. Qualitative research for education. Boston: Allyn \& Bacon, 1982.

BOURDIEU, P. 0 poder simbólico. Rio de Janeiro: Bertrand Brasil, 1989.

CAMBA, S. V. ONGs e escolas públicas. 2004. 205 p. Dissertação (Mestrado em Educação) - Faculdade de Educação, Universidade de São Paulo, São Paulo, 2004.

CANDIDO, A. Vários escritos. São Paulo: Duas Cidades, 1995.

COELHO, N. N. Literatura infantil: teoria, análise e didática. São Paulo: Moderna, 2002.

EITERER, C. L. Uma leitura possível: um estudo sobre a formação do leitor no ensino médio. 2001. 173 p. Tese (Doutorado em Educação) - Faculdade de Educação, Universidade de São Paulo, São Paulo, 2001.

FREIRE, P. Educação como prática da liberdade. Rio de Janeiro: Paz e Terra, 2002.

JAUSS, H. R. A história da literatura como provocação à teoria literária. São Paulo: Ática, 1994.

0 prazer estético e as experiências fundamentais da poiesis, aithesis e katharsis". In: LIMA, L. C. (Org.). A literatura e 0 leitor. São Paulo: Paz e Terra, 2002. p. 85-103.

KLEIMAN, A. (Org.). Os significados do letramento. Campinas: Mercado de Letras, 1995.

LIMA, L. C. (Org.). A literatura e o leitor. São Paulo: Paz e Terra, 2002.

MARX, K. A ideologia alemã. São Paulo: Martins Fontes, 2002.

SCHERER- WARREN, I. ONGs na América Latina: trajetória e perfil. In: VIOLA, E. (Org.). Meio ambiente, desenvolvimento e cidadania: desafio para as ciências humanas. São Paulo: Cortez, 1995. p. 161-180.

SMITH, F. Compreendendo a leitura. Porto Alegre: Artes Médicas, 1999.

. Leitura significativa. Porto Alegre: Artes Médicas, 2003. 
SOARES, M. Letramento, um tema em três gêneros. Belo Horizonte: Autêntica, 2003.

TEZZARI, N. S. A constituição do aluno leitor: um estudo etnográfico. 2005. 252 p. Tese (Doutorado em Psicologia) - Instituto de Psicologia, Universidade de São Paulo, São Paulo, 2005.

TOURAINE, A. 0 retorno do ator: ensaio sobre sociologia. Lisboa: Instituto Piaget, 1989.

Recebido em 18.05.09

Aprovado em 09.09.10

Ana Shitara Inglesi é Mestre em Educação pela Universidade de São Paulo, professora de Português/Inglês e de Educação infantil bilíngüe. Email: asinglesi@gmail.com

Idméa Semeghini-Siqueira é doutora em Linguística pela Universidade de São Paulo, fez pós-doutorado na Université Paris 13, é professora da Faculdade de Educação da Universidade de São Paulo, e coordenadora do grupo de pesquisa Diversidade Cultural, Linguagem, Mídia e Educação. 